\title{
Violence against Women with Breast Neoplasms
}

\author{
Bianca Maria Oliveira Luvisaro ${ }^{1}$ and Clícia Valim Côrtes Gradim ${ }^{2}$ \\ 1. Medical School, UFMG (Federal University of Minas Gerais), Belo Horizonte 30000-000, Minas Gerais, Brazil \\ 2. Nursing School, UNIFAL (Federal University of Alfenas), Alfenas-37130-000, Minas Gerais, Brazil
}

\begin{abstract}
The aim of this study is to assess the occurrence and type of violence suffered by women with breast cancer in the High Complexity Care Unit of a municipality in the South of Minas and patients in a support group of the University of the South of Minas Gerais. For that aim, a descriptive-exploratory methodology was applied through the quantitative method. Data were collected through a semi-structured form applied in individual interviews over a period of three months. We interviewed 57 patients and among those, 20 women $(35.08 \%)$ reported having experienced some form of violence at some stage of their life, and the most frequently mentioned was the psychological violence followed by physical aggression. Although it was possible to identify that violence against affected these women, complaints against the aggressor were not affected.
\end{abstract}

Key words: Violence, woma, breast neoplasms, nursing.

\section{Introduction}

Violence against women and BC (breast cancer) has been a public health problem in Brazil and worldwide that generates consequences in the life and health of the affected women $[1,2]$.

Studies have shown that women who were diagnosed with breast cancer, besides presenting risk factors, also had the experience of stressors before receiving the diagnosis $[3,4]$.

Thus, this study sought to identify the women diagnosed with breast cancer who have suffered some kind of violence. For this, it is necessary to present the context of violence against women.

Violence has, for many years, reflected a situation of domination and power over a population or an individual and is rooted in social relations, which, in turn, are characterized as a highly complex problem that affects everyone, regardless of social issues, financial situation, gender, age, religion or race [5].

Nowadays, violence has acquired a proportion of great social significance, not because it is occurring more frequently, but because it is becoming gradually

Corresponding author: Bianca Maria Oliveira Luvisaro, nurse specialist in oncology, master student, research fields: nursing, medical oncology and women's health. more publicized, investigated and mainly more studied [2].

Thus, society has been increasingly experiencing violence in their various fields, whether in its physical, moral or social form, defined as:

"The use of physical force or power, real or in form of threats, against oneself, against another person, or against a group or community, that either results in or has any chance of resulting in injury, death, psychological harm, developmental disability or deprivation" [5].

Violence has represented, since the beginning of the century, a public health problem in Brazil and in other countries due to the high number of victims and the severity of the problem.

It is observed that the violence ends up leaving physical, psychological, emotional and social consequences, such as depression, anxiety, stress, alcohol and drug abuse, suicide, gastrointestinal disorders, physical consequences, and may even lead to the development of psychosomatic diseases $[6,7]$.

Today, violence is classified in five ways [8], as follows:

(1) physical violence, understood as any behavior that offends the physical integrity or health; 
(2) psychological violence, understood as any behavior that causes emotional damage and decreased self-esteem or that harm and disturb the full development of the person or seeks to degrade or control the person's actions, behaviors, beliefs and decisions by threat, embarrassment, humiliation, manipulation, isolation, constant vigilance, contumacious persecution, insult, blackmail, ridicule, exploitation and limitation of the right to come and go or any other way that is detrimental to the psychological health and self-determination;

(3) sexual violence, understood as any behavior that constrains the person to witness, to maintain or to participate in unwanted sexual intercourse, through intimidation, threat, coercion or use of force; that may induce the person to market or use in any way the person's sexuality, preventing the person from using any contraceptive method or the force to marriage, pregnancy, abortion or prostitution by coercion, blackmail, bribery or manipulation; or that limits or annuls the exercise of sexual and reproductive rights;

(4) patrimonial violence, understood as any behavior that constitutes retention, subtraction, partial or total destruction of the person's objects, work tools, personal documents, goods, values and rights or economic resources, including those intended to meet the person's needs;

(5) moral violence, understood as any behavior that constitutes slander, libel or outrage.

Domestic violence includes all forms of violence within the family environment, delimited by acts performed by partners or ex-partners who live together or not in the same household, and that is perpetrated or not in the same place [9].

Violence, because it is considered a human phenomenon, has to be analyzed within the historical and cultural context in which it occurs, for violent acts in some cultures may not be so in others [8].

Therefore, for a long time, violence against women was considered a natural way in family relations because of the power that the man had over marriage and over the relationship [10].

However, the woman victim of domestic violence started to have a legal backing from 2006 onwards, due to the struggle of a woman who became paraplegic as a result of violence. As a result of this struggle, the Law No. 11.340/2006, known as the Law Maria da Penha, was approved in 2006. This law creates mechanisms to restrain and prevent domestic and family violence against women and encourages the denunciation of the aggressor [11].

So, when trying to make a parallel between the women who are victims of violence and those who are diagnosed with breast cancer, in both situations, a delay is observed in seeking help. In the first situation, the victims do not report the aggressor, and in the second, there is a delay to seek medical attention. In both situations, there is risk of increasing physical and psychological trauma [4-12].

Modesitt et al. [12] reported on their studies with American women with cancer in the breast, ovary and endometrium, that the diagnosis of cancer may have an association with sexual and physical violence. This increases the risk of health problems. Violence against women was observed in $48.5 \%$ in this group, and $22.44 \%$ of this group were patients with breast cancer.

However, tumors have been associated with accursed or negative experiences and are characterized as "social cancers", in which the violence, family disintegration and drug use have been reported as troublemakers and termed as cancer [13].

$\mathrm{BC}$ (breast cancer) is the most common tumor among women in the world. And it is a complex disease that generates intense impact on the lives of women due to the invasive treatments and the uncertainty of cure. It is a disease most prevalent among women older than 40 years, with precocious menarche, late menopause, first birth after the age of 30 years and nulliparity and also the genetic factor and/or first-degree relatives, as RF (risk factors) [14].

Risk factors also include age, exposure to ionizing radiation, obesity, diet, geographic location, alcohol 
consumption, use of oral contraceptives and hormone replacement therapy [1-15].

As methods for early detection, there is screening through clinical breast examination, ultrasound, mammography, puncture and/or biopsy. After diagnosis, breast surgery, radiation therapy for locoregional treatment, chemotherapy and hormone therapy for systemic treatment are applied as therapeutic modalities [1].

Diagnosis of the disease is seen in many cultures as an act of penalty and punishment, leading women to associate cancer as a violence in their own body, especially when they make associations with invasive treatments as described above [13].

Faced with the above, and taking into account the lack of studies related to the two issues, the results of this work will make possible to verify if violence occurs against women diagnosed with breast cancer.

\section{Material and Methods}

Study with quantitative, descriptive and exploratory approach that used the population of women diagnosed with breast cancer, who were enrolled in a High Complexity Assistance Unit (Unacon) of a municipality in Southern Minas and who were attending the support group of a University of Southern Minas.

The study was approved by the REC (Research Ethics Committee) of the Federal University of Alfenas-MG, under Protocol No. 183,246 (Appendix A), according to the $\mathrm{NCH}$ (National Council of Health) 466/12 [16].

Data were collected by authors after prior contact through telephone and signature of the Informed Consent. We used an instrument with 22 questions divided into three parts: identification and characterization of the sample, history of the disease, kind of aggression and conduct adopted.

Data were collected during the months of May and July 2013, so that the sample used was non-probabilistic, by convenience. The criteria for inclusion or eligibility were women: diagnosed with breast cancer or who are undergoing treatment and rehabilitation; who had ability for verbal communication; who agreed to participate in the study and signed the Informed Consent form.

Thus, the study sample consisted of 57 female patients with breast cancer who use the services of high complexity of a city in the South of Minas and the services of the support group of a University of Southern Minas.

Data were organized, validated and stored in a database structured in an electronic spreadsheet and analyzed using SPSS Version 17.

The variables were organized and presented with frequencies in order to characterize the distribution of facts and in accordance with the objective; associations between questions in some variables were made.

Results were divided into three stages: the first referred to the characterization of the sample, the second, to the period of discovery of the disease, and the third and final, in relation to the reported violence.

\section{Results and Analysis}

Table 1 shows the characterization of the sample as for socio-economic characteristics according to the collected data.

The characterization of the sample in Table 1 was formed by women with an average age of 58 years, reinforcing the prevalence of the disease in this stage of life, and the extreme ages were 87 years and 21 years.

Studies have shown that age is a major risk factor for BC. In this study, data of age were similar to other studies in showing that the age group with the highest prevalence was 50 60 years [17], nearly $6.5 \%$ of cases of this cancer occur in women under 40 years and $0.6 \%$ in women under 30 years [18]. What calls attention in this study is that $10.04 \%$ of women are younger than 40 years, and younger than 30 years. Young age is often mentioned as a factor dependent on poor prognosis [19]. 
Table 1 Socio-demographic data of the sample.

\begin{tabular}{|c|c|c|c|}
\hline Variables & & Absolute No. $=57$ & Relative No. $(\%)$ \\
\hline \multirow{7}{*}{ Age group } & $21 \sim 30$ & 3 & 5.2 \\
\hline & $31 \sim 40$ & 3 & 5.2 \\
\hline & $41 \sim 50$ & 10 & 17.54 \\
\hline & $51 \sim 60$ & 15 & 26.31 \\
\hline & $61 \sim 70$ & 12 & 21.05 \\
\hline & $71 \sim 80$ & 12 & 21.05 \\
\hline & $81 \sim 90$ & 2 & 3.5 \\
\hline \multirow{5}{*}{ Marital status } & Married & 28 & 49.12 \\
\hline & Widow & 13 & 22.80 \\
\hline & Divorced/separated & 6 & 10.52 \\
\hline & Single & 4 & 7.01 \\
\hline & Stable relationship & 6 & 10.52 \\
\hline \multirow{5}{*}{ Level of education } & Incomplete elementary school & 25 & 43.85 \\
\hline & Complete elementary school & 13 & 22.80 \\
\hline & Incomplete highschool & 1 & 1.75 \\
\hline & Complete highschool & 7 & 12.28 \\
\hline & Complete superior education & 11 & 19.30 \\
\hline \multirow{4}{*}{ Profession } & Group 2: Specialists in intellectual and scientific activities & 5 & 8.76 \\
\hline & Group 3: Technicians and intermediate professions & 4 & 7.01 \\
\hline & $\begin{array}{l}\text { Group 5: Workers of personal services, protection and security and } \\
\text { sellers }\end{array}$ & 8 & 14.02 \\
\hline & Group 9: Unqualified workers & 40 & 70.17 \\
\hline \multirow{3}{*}{ Family Income } & 1 to 2 minimum wages & 31 & 54.38 \\
\hline & 2 to 4 minimum wages & 22 & 38.60 \\
\hline & 5 to 7 minimum wages & 4 & 7.02 \\
\hline \multirow{3}{*}{ Belief } & Catholicism & 36 & 63.15 \\
\hline & Protestantism & 15 & 26.31 \\
\hline & Spiritist doctrine & 6 & 10.52 \\
\hline
\end{tabular}

Source: Authors, Alfenas-MG, 2013.

Regarding marital status, $49.12 \%$ declared themselves married and $43.85 \%$ had incomplete primary education, declaring financial income of one to two minimum wages $(54.38 \%)$ and $63.15 \%$ declared themselves Catholic. This fact coincides with the profile of the municipality, where the average income is two minimum wages and the illiteracy rate is $7.8 \%[20]$.

In this study, the rate of women with incomplete elementary school was $43.85 \%$. It is known that the level of education is essential for the health care. Schooling increases the chance of women search for clinical breast examination and make mammography more frequently, helping with earlier diagnosis [21].
As regards the profession, the Brazilian Classification of Occupations-BCO which recognizes, give names and codes the titles and describes the characteristics of the occupations of the Brazilian labor market and occupations are classified into 10 groups: Group 0-professions of the army; Group 1 -representatives of the legislative power and organs; Group 2-specialists of intellectual and scientific activities; Group 3-technicians and professions of intermediate level; Group 4-administrative staff; Group 5-workers of personal services, protection and security and sellers; Group 6-farmers and skilled workers in agriculture, fishing and forestry; Group 7-workers skilled in industry, construction and 
craftsmen; Group 8-operators of installations and machinery and assembly workers; Group 9-unqualified workers [22].

Thus, it is observed in Table 1 that Group 9 was the one that stood out with $70.17 \%$, and this group includes activities related to the home, retirement and students. This identifies a group of women who are mostly financially dependent of their companions.

Regarding the second stage and the data on history of the illness, it was observed that $16(28 \%)$ of the participants in the sample were in the initial stage of the disease and/or treatment, that is, were diagnosed between one and eight months and they were undergoing treatment. Fourteen women (25\%) were in the first after diagnosis of breast cancer; nine women $(15 \%)$ with two years, 10 women $(18 \%)$ with three years, one woman $(2 \%)$ with one year and seven women $(12 \%)$ free of the disease for more than five; phase in which they only make the medical follow-up.

When comparing the age of participants with the age at the moment of discovery of diagnosis, it can be seen that the initial diagnosis of the problem prevailed within the range of 58 years, which was the age with higher incidence of the disease [19].

When asked about the discovery of the initial diagnosis of the disease, $49 \%$ participants reported that it was through self-examination of breasts that they noticed some kind of change and looked for medical care. This fact shows that campaigns of health promotion and prevention have been effective and that women have learned to touch themselves without fear or shame. The other women discovered the cancer through health services, and 33\% through routine tests where the clinical breast exam by a health professional was carried out showing changes in tests such as mammography and ultrasound, and $18 \%$ reported that the cancer was discovered through to other types of medical assistance.

However, when analyzing this study we note that although women perceive significant changes in their body, many of them delayed to look for specialized care, and this led to a late diagnosis, often in advanced stage.

As for the risk factors, there was no proven evidence for each type. However, it is clear that no single factor is as important as the age for the development of breast cancer [17].

Table 2 shows the types of risk factors cited by participants, and in this question, each participant could select more than one factor.

Looking at the Table 2, it is noted the presence of variable and non-variable RF. The non-modifiable variables, such as age, hormonal and reproductive variables are the most considered in the etiology of breast cancer, and have a general biological plausibility the exposure to estrogens, progestins and other hormones with carcinogenic potential.

Thus, it is noted in Table 1 that cases of cancer in the family had a high percentage and may be related to genetic factors such as mutations in the hormone called BRCA1/2. These genes produce proteins that regulate cell multiplication mechanism, and are known as tumor suppressors. Mutations involve loss of that control, and these altered genes are hereditarily transmitted [23].

The genetic factor of personal history may be present in about $5 \sim 10 \%$ of cases [24]. However, in this study, we reported a positive incidence of cancer in the family of $28.07 \%$ participants, and when analyzing women younger than 30 years, this percentage was $100 \%$.

Table 2 Risk factors for breast cancer.

\begin{tabular}{lcl}
\hline Risk factors* & $\begin{array}{l}\text { Absolute } \\
\text { No. }\end{array}$ & $\begin{array}{l}\text { Relative No. } \\
(\%)\end{array}$ \\
\hline Cases of cancer in the family & 16 & 28.07 \\
Early menarche & 5 & 8.77 \\
Nulliparity & 8 & 14.03 \\
Late pregnancy ( $>$ 35 years) & 6 & 10.52 \\
Never breastfed & 14 & 25.56 \\
$* *$ HOC use for consecutive years & 27 & 47.36 \\
Sedentary lifestyle & 9 & 15.78 \\
Obesity & 9 & 15.78 \\
Hormone replacement & 20 & 35.08 \\
Late menopause & 7 & 12.28 \\
\hline
\end{tabular}

Source: Authors, Alfenas-MG, 2013.

*More than one answer;

**HOC (hormonal oral contraceptive). 
However, little is known about the prevalence of this factor in the Brazilian population. The highest prevalence rates analyzed in the study of Paiva [17] were $13.10 \%$ for cases of BC among first-degree relatives. Thus, this factor should be analyzed with caution as the finding may be due to the characteristics of chance.

Regarding the use of HOC, the study of Schor et al. [25] in São Paulo with 1,157 women between 10 and 49 years shows a prevalence of $35.3 \%$ for the use of oral contraceptives. So, this study of women with breast cancer also demonstrated the HOC use by the majority of the sample, that is, $47.36 \%$.

However, according to INCA, it is still not certain the association between the use of birth control pills and an increased risk for breast cancer. Women who used oral contraceptives with high estrogen doses, who used the medication for a long period and those who used it at early age, before the first pregnancy, may be more likely to have the disease [21].

Other risk factors that have called attention are endocrine aspects, which are related mainly to the estrogenic stimuli, either endogenous or exogenous, with increased risk in longer times of exposure [19]. The following factors had also increased risk in this sample: women with history of early menarche (age at first menstrual period less than 12 years), late menopause (after age 50), late pregnancy (after 30 years), nulliparity and with therapy of hormone replacement post menopause, especially if extended for more than five years.

As for the modifiable variables, it is observed in Table 1 that $25.56 \%$ of the women interviewed had never breastfed their children.

It is known that breastfeeding is a protective factor against the $\mathrm{BC}$ as its protective effect may be associated with full differentiation of breast cells and less time of exposure to the action of sex hormones, which are reduced during amenorrhea induced by lactation. Moreover, the intense exfoliation of the breast tissue and the massive apoptosis of epithelial cells resulting from feeding may reduce the risk of breast cancer through the elimination of cells that have suffered some potential DNA (deoxyribonucleic acid) damage [26, 27].

As for the modifiable RF obesity and sedentary lifestyle, we observe a relative percentage of $15.78 \%$. A study demonstrated that physical inactivity and increased body mass in postmenopausal periods promote the increase of the level of circulating estrogen because adipose tissue is the primary site of estrogen synthesis in women after menopause and promotes the increase of insulin and of the circulating insulin-like growth factor (IGF-1) [27]. These substances along with other pro-inflammatory factors, such as TNF (tumor necrosis factor), interleukin and C-reactive protein produced by adipocytes, induce cell cycle progression and inhibition of apoptosis, thereby increasing the risk of development of cancer.

When asked about the type of treatment that they were submitted, most women $(83.45 \%)$ reported that they had been through some type of surgery and had undergone chemotherapy $(89.47 \%)$ and radiotherapy $(42.10 \%)$ as adjunctive treatment. These data show the profile of the proposed treatment for this neoplasm and, in this sample, all had the Stage III or above this stage.

In relation to current treatment, chemotherapy (45.61\%) and hormone therapy (45.61\%) were equal. In hormone therapy, the use of tamoxifen in $35.8 \%$, anastrozole in $8.77 \%$ and xeloda in $1.75 \%$ stood out.

When questioned on the period of diagnosis with emotional factors experienced, $52.62 \%$ of women said yes, as seen in Table 3.

By analyzing these data, it is clear that emotional factors experienced in the earlier period of the disease

Table 3 Cause of emotional crises experienced.

\begin{tabular}{lcc}
\hline Emotional crisis & Absolute No. & Relative No. \\
\hline Family problems & 16 & $28.07 \%$ \\
Death in the family & 7 & $12.28 \%$ \\
Illness in the family & 1 & $1.75 \%$ \\
Husband's betrayal & 6 & $10.52 \%$ \\
Total & 30 & - \\
\hline
\end{tabular}

Source: Authors, Alfenas-MG, 2013. 
Table 4 Type of violence reported.

\begin{tabular}{lcc}
\hline Type of violence & Absolute No. & Relative No. (\%) \\
\hline Psychological & 13 & 65 \\
Physical & 7 & 35 \\
Total & 20 & 100 \\
\hline
\end{tabular}

Source: Authors, Alfenas-MG, 2013.

Table 5 Status of cases when there was complaint.

\begin{tabular}{lll}
\hline State of the process & Absolute No. & Relative No. \\
\hline Ongoing process & 3 & $15.0 \%$ \\
\hline Emprisonment & 2 & $10.0 \%$ \\
\hline $\begin{array}{l}\text { Distance limitation from the } \\
\text { victim }\end{array}$ & $5.0 \%$ \\
$\begin{array}{l}\text { Prohibition to communicate } \\
\text { with the victim }\end{array}$ & $5.0 \%$ \\
\hline Total & 7 & - \\
\hline
\end{tabular}

Source: Authors, Alfenas-MG, 2013.

are prone to increased stress in the lives of these women, as they are present in the day-to-day of the interviewees and increase the tension and apprehension within the family environment, generating often quarrels and dissensions. However, one can not say that stress promotes cancer.

In the third stage the participants were questioned in relation to the violence against women, resulting in 20 women (35.08\%) who reported that had suffered some kind of violence, and 17 (85\%) informed the household as the site of aggression, featuring domestic violence.

When asked if during childhood they had witnessed some form of violence, 29 (50.87\%) women said yes.

When comparing the data of those who suffered violence with those women who during childhood witnessed scenes of violence in the home, there was a relative percentage of $10.52 \%$, that is, six women who witnessed violence as children ended up at some point in their adulthood suffering some form of violence. This shows that living with violence cause this to be repeated, showing resilience in face of the fact and allowing the cycle to repeat.

Table 4 refers to the type of violence suffered at some stage of life of women with breast cancer.

When evaluating the type of violence suffered, it was found that the psychological was more frequent than physical violence. These kinds of violence are most commonly found in the environment where people are close to each other, characterizing the environment of domestic violence [4].

When asked about who was the perpetrator of the situations experienced, the present and former partner were the most cited, in $65 \%$ and $35 \%$ of cases respectively, not different from the pattern found in other studies [11].

As for reporting the violence to the competent institutions, seven participants (35\%) said that they did such complaint, and Table 5 shows in what situation are the processes.

Among the twenty women who reported violence (35.08\%), it is observed that few had made the complaint against the aggressor. It is believed that many keep silent by fear, emotional dependency, embarrassment of having their life investigated and impunity [28].

\section{Discussion}

Based on the results and analysis of data, we can highlight that domestic violence in the group of women with breast cancer was present in several cycles of life, even during childhood. We see that these women have come from childhood witnessing scenes of violence and with tension and apprehension of the family environment as stressors.

Many interviewees had reduced opportunities for study and/or professional training, and this reflects in their lives even in present days, especially with regard to occupation and financial aspects.

According to some studies shown by Filleti [29], it is shown that stress favors the development of cancer because it exposes the individual to a carcinogen that can trigger genetic propensity for the disease, and when associated with behavioral factors such as the acts of smoking, alcohol intaking and escape response and rigid denial of conflicts, favor towards the modifiable risk factors [29].

Thus, it was observed that in the study population, six (30\%) patients who had witnessed scenes of 
violence during childhood and that somehow suffered some kind of violence were diagnosed with breast cancer.

Data analysis allowed us to observe that women who reported violence $(35.08 \%)$ had the same municipal index. Regarding the type of violence, psychological was the most mentioned. This is characterized by insult or public humiliation, intimidation and threats and that is the one that occurs in environments where people know each other (65\%). Physical violence, which is characterized by attacks such as punching, kicking, shoving, was the second most reported type of violence by the group (25\%).

However, the psychological violence that prevailed in relation to other forms of violence, though not leaving marks, is cause of suffering and the cause of numerous diseases whose symptoms are often not perceived by health professionals [9].

Studies [9-30] have shown that psychological violence is the one that mostly affected against women, and the home was the site where aggression took place, and this kind of violence is often followed by physical aggression. Therefore, the present study corroborates the statements made by the authors. Our data is similar to other studies where psychological/emotional (56.4\%) and physical (32.1\%) violence were found [31].

The domestic space in which there is violence against women happens with the complicity and indifference of society, which often turns out to be a space of free-will and aggression [31].

As for the aggressor, this was mainly the present partner and the former husband, further reinforcing gender violence practiced within the family environment that evolves with the cycle of violence. A study found [31] a high prevalence of these offenders (73.4\%). In this process, violence was one of the man's mechanisms of domination over women, legitimized by institutions such as family and marriage. The home can be an environment of conflict and intrigue generating negative consequences for the emotional balance of the victims. The family and the husband support is very important for women who receive a diagnosis of cancer, helping them in the acceptance and body change that the disease brings [32], mainly because the experience of coping with the disease may affect family relationships, cause stress, tension and reactivation of latent conflicts, because the disease alters the social role of the sick individual and the family dynamics $[33,34]$.

Importantly, the experience of receiving a diagnosis of cancer causes in patients the awakening of existential reflections related to the meaning of life and death [35].

The sample participants reported many emotional factors that they experienced before the discovery of diagnosis, among these we can highlight the family problems and death in the family, all favoring further stressor agents.

The loss of a loved one generates many consequences on the psychological and mental state, and many can not accept the death of a close person. The same happens with the diagnosis of cancer. Many cling to the denial phase, becoming a long, insidious and traumatic phase, which increases the presence of stress and strain in the lives of women [35].

When comparing the level of violence found in this study (35.08\%) in the present study, lower levels were found by Modesitt et al. [12] and Coker et al. [36] where the rate of women with breast cancer and who have suffered some form of violence during life was $22.44 \%$ and $36 \%$, respectively.

However, as it was seen in these studies [12,36], it is not possible to make comparisons and concrete statements about violence being a factor to the diagnosis of breast cancer. However, we can say that violence brings physical, mental and emotional consequences for the lives of these women, causing the emotional and psychological factor to be affected in such a way that ends up increasing stress factors.

Yet, embrittlement of the victims may include permanent effects on self-esteem and self-image, making them less likely to protect themselves, less sure 
about their value, of their personal boundaries and prone to accept victimization as part of their womanhood.

\section{Conclusions}

Violence against women is a widespread problem that crosses racial and socio-economic borders, and its impact on women's health has been slowly elucidated.

The data confirmed that $35.08 \%$ of women with breast cancer reported having experienced some form of violence during their lifetime, with the psychological being the most frequent followed by the physical violence; with a rate equal to the general population.

The partner was cited as the aggressor and the home as the most common site, which features domestic violence within the family.

It is not possible to say that domestic violence contributes to the onset of cancer, but it is known that favors the appearance of other risk factors such as increased anxiety, depression, smoking, physical inactivity and obesity. But it would not be important to consider the presence of violence in the history of women.

Still, this study has shown that the violence suffered by these women was not followed by complaint of the aggressor, which leads to the process of "routinization of violence" in which they believe the promises of partners when they say that they will not attack them again.

It is believed that the effects of violence and possible relations with the tumor biological pathways deserve further exploration and healthcare and that professionals should be encouraged to detect women who are victims of violence to improve care.

\section{References}

[1] INCA (Instituto Nacional de Câncer). 2004. "Consensus for the Management of Breast Cancer." Revista Brasileira de Cancerologia 50 (2): 77-90.

[2] Lisboa, M. T. L., Moura, F. J. M., and Reis, L. R. 2006. "Violence of the Everyday and in the Nursing Work: Apprehensions and Expectations of the Students from a
Course of Graduation in Nursing of Rio de Janeiro." Escola Anna Nery 10 (1): 81-6.

[3] Da Silva, G., and Dos Santos, M. A. 2008. "Does This Never End? Investigating the Universe of the Breast Cancer Post-treatment." Texto e Contexto Enfermagem 17 (3): 561-8.

[4] Neme, C. M. B., and Lipp, M. E. N. 2010. "Psychological Stress and Coping in Women with and without Cancer." Psicologia: Teoria e Pesquisa 26 (3): 475-83.

[5] Minayo, M. C. S. 2006. Violence and Health. Rio de Janeiro: Fiocruz.

[6] Paulo, R. D., and Paro, E. 2009. Domestic Violence against Women: A Vision in Cognitive-Behavioral Approach. Mato Grosso: UNIVAG,.

[7] Rosa, R., Boing, A. F., Schraiber, L. B., and Coelho, E. B. S. 2010. "Violence: Concept and Experience among Health Sciences Undergraduate Students." Interface-Comunicação, Saúde, Educação 4 (32): 81-90.

[8] Cavalcanti, S. V. S. F. 2007. Domestic Violence: Analysis of the Law "Maria da Penha", No. 11.340/06. Salvador: PODIVM.

[9] Schraiber, L. B., Oliveira, A. F. P. L., Junior, I. F., and Pinho, A. A. 2002. "Violence against Women: A Study in a Primary Healthcare Unit." Revista de Saúde Pública 36 (4): 470-7.

[10] Ritt, C. F., Cagliari, C. T. S., and Costa, M. M. 2009. Violence Committed against Women Understood as Gender Violence. Rio Grande do Sul: UFRGS.

[11] Domingues, B., and Machado, K. 2010. "Maria da Penha Law: Limits or Possibilities?.” RADIS: Comunicação em Saúde 92: 10-5.

[12] Modesitt, S. C., Gambrell, S. C., Cottrill, H. M., Hays, L. R., Walker, R. J., Shelton, B. J., et al. 2006. “Adverse Impact of a History of Violence for Women with Breast, Cervical, Endometrial, or Ovarian Cancer." Obstetrics e Gynecoloy 107 (6): 1330-6.

[13] Gomes, R., Skaba, M. M. V. F., and Vieira, R. J. S. 2002. "Reinventing Life: A Proposal for a Socio-Anthropological Approach to Breast Cancer." Caderno Saúde Pública 18 (1): 197-04.

[14] BRASIL. 2013. Ministry of Health National Cancer Institute (INCA): Cancer Incidence Estimates in Brazil. Rio de Janeiro: BRASIL.

[15] Guerra, M. R., Gallo, C. V. M., and Mendonça, G. A. S. 2005. "The Risk of Cancer in Brazil: Tendencies and Recent Epidemiologic Studies." Revista Brasileira de Cancerologia 51 (3): 227-34.

[16] Ministry of Health, National Health Council of Brazil. 2013. "Resolution No. 466 of 12 December 2012. Guidelines and Regulatory Standards for Research Involving Human Subjects. Bioética. Brasília, Seção 1, 12, 59-2.” Accessed October 1, 2015. http://www.conselho.saude.gov.br/web_comissoes/conep/ 
index.html.

[17] Paiva, C. E., Ribeiro, B. S., Godinho, A. A., Meirelles, R. S. P., Silva, E. V. G., Marques, G. A., et al. 2002. "Risk Factors for Breast Cancer in Juiz de Fora (MG): A Case-Control Study." Revista Brasileira Cancerologia 48 (2): 231-7.

[18] Clagnan, W. S., Andrade, J. M., Carrara, H. H. A., Tiezzi, D. G., Reis, F. J. C., Marana, H. R. C., et al. 2008. "Age as an Independent Prognostic Factor in Breast Cancer." Revista Brasileira Ginecologia Obstetrícia 30 (2): 67-74.

[19] INCA (Instituto Nacional de Câncer). 2013. National Program for Breast Cancer Control. Rio de Janeiro: INCA.

[20] IBGE (Instituto Brasileiro de Geografia e Estatística). 2012. Demographic Census 2010. Rio de Janeiro: IBGE.

[21] Schneider, I. J. C., and D'orsi, E. 2009. "Five-Year Survival and Prognostic Factors in Women with Breast Cancer in Santa Catarina State, Brazil." Caderno de Saúde Pública 25 (6): 1285-96. (in Portuguese)

[22] Ministry of Health, Ministry of Labour, Brazil. 2002. "The Brazilian Classification of Occupations-CBO. No. Ministerial Order. 397 of 9 October." Accessed September 1, 2015. http://www.mtecbo.gov.br/cbosite/ pages/legislacao.jsf.

[23] Pinho, V. F. S., and Coutinho, E. S. F. 2005. "Risk Factors for Breast Cancer: A Systematic Review of Studies with Female Samples among the General Population in Brazil." Caderno Saúde Pública 21 (2): 351-60. (in Portuguese)

[24] Pinho, V. F. S., and Coutinho, E. S. F. 2007. "Variables Associated with Breast Cancer in Clients of Primary Healthcare Units.” Caderno de Saúde Pública 23(5): 1061-9. (in Portuguese)

[25] Schor, N., Ferreira, F. A., Machado, V. L., França, A. P., Pirotta, K. C. M., Alvarenga, A. T., et al. 2000. "Women and Contraception: Knowledge and Use of Contraceptive Methods." Caderno de Saúde Pública 16 (2): 377-84. (in Portuguese)

[26] Inumaru, L. E., Silveira, E. A., and Naves, M. M. V. 2011. "Risk Factors and Protection for Breast Cancer: A
Literature Review.” Caderno Saúde Pública 27 (7): 1259-70. (in Portuguese)

[27] WCRF/AICR (World Cancer Research Fund/American Institute for Cancer Research). 2007. Food, Nutrition, Physical Activity, and the Prevention of Cancer: A Global Perspective. Washington, D.C.: AICR.

[28] Garbin, C. A. S., Garbin, A. J. I., Dossi, A. P., and Dossi, M. O. 2006. "Domestic Violence: An Analysis of Injuries in Female Victims." Caderno Saúde Pública 22 (12): 2567-73. (in Portuguese)

[29] Filete, M. 2007. Behaviors Analysis of History Events in Women with Breast Cancer. Campinas: PUC-Campinas.

[30] Schraiber, L. B., Oliveira, A. F. P. L. D., Junior, I. F., Diniz, S., Portella, A. P., Ludermir, A. B., et al. 2007. "Prevalence of Intimate Partner Violence against Women in Regions of Brazil." Revista de Saúde Pública 41 (5): 1-10.

[31] Galvão, E. F., and Andrade, M. F. 2004. "Violence against Women: Analysis of Cases Attended in a Women Care Centre in a Municipality in Southern Brazil." Saúde e Sociedade 13 (2):89-99. (in Portuguese)

[32] Carvalho, C. C., and Gradim, C. V. C. 2014. "Stressful Situations in Breast Cancer." J. Health. Biol. Sci. 2 (4): 208-12.

[33] Marques, T. M. 2005. "Conjugal Violence: Study on the Permanence of Women in Abusive Relationships." Master thesis, Universidade Federal de Uberlândia.

[34] Carvalho, C. S. U. 2008. "Attention to the Needs of Cancer Patients' Families." Revista Brasileira de Cancerologia 1 (54):87-6.

[35] Ambrósio, D. C. M., and Santos, M. A. 2011. "Experiences of Family Members of Women with Breast Cancer: A Phenomenological Approach." Psicologia: Teoria e Pesquisa 27 (4): 475-84.

[36] Coker, A. L., Follingstad, D., Garcia, L. S., Williams, C. M., Crawford, T. N., and Bush, H. M. 2012. "Association of Intimate Partner Violence and Childhood Sexual Abuse with Cancer-Related Well-Being in Women." Journal of Women's Health 21 (11): 1180-8. 